\title{
Materials Budgets in the Electronic Age: A Survey of Academic Libraries
}

\author{
Frank R. Allen
}

Academic libraries face a host of expenditures for products and services, which, though not materials per se, provide access to materials. The extent to which libraries fund these services through materials budgets is the focus of a survey of academic librarians in the United States and Canada. In September 1994, the author sent questionnaires to the head librarians of 230 academic libraries. The survey generated a 76.9 percent response rate. Over two-thirds of the respondents indicated they allocate less than six percent of their materials budgets to nondata resources. Seven out of ten respondents agree, however, that it is natural for materials budgets to absorb certain technology costs. In addition, only 23 percent think that materials budgets should be limited to materials in a traditional sense. These findings suggest that most librarians are continuing to allocate materials budgets in a traditional manner, while recognizing the inevitable shifts in allocation of scarce resources.

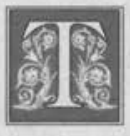

he evolution of the electronic library is forcing librarians to examine critically how to allocate scarce financial resources in academic libraries. Libraries face growing outlays for products, systems, and services in support of electronic access and delivery. Examples include computer software, computer hardware, file storage costs, software and hardware maintenance, preprocessing and servicing, and licensing fees. Because they are relatively new phenomena, these services typically have little, if any, dedicated funding. Therefore, librarians are looking for ways to pay for these new services. Do librarians fund these nontraditional expenses from the materials budget, operating funds, outside funding, or some combination of all three sources? The traditionalist may object to using the materials budget on the grounds that it is philosophically inappropriate as well as illtimed, given the erosion of purchasing power from two decades of serials inflation. Others may object to using the operating budget if it crowds out essential operating needs. If the library is not able to find the funding internally, it faces the task of persuading campus or outside agencies to support these needs. In an era of higher-education downsizing, this can be a challenge. Furthermore, campus budget offices and outside agencies do

Frank R. Allen is Head, Administrative Services, University Library Services, Virginia Commonwealth University, Richmond; e-mail: frallen@gems.vcu.edu. 
not always comprehend this library transformation and the resulting shift in funding requirements.

\section{Literature Review}

A ten-year retrospective review of library and information science literature reveals a widening arc of discussion on the resources appropriately funded through the materials budget. Several position papers published in 1986 and 1987 discuss the practice of funding online search costs through the materials budget. Jay Martin Poole and Gloriana St. Clair argue that online search costs deserve a place in the materials budget by satisfying legitimate educational and research needs. The practice should be only a temporary measure, however, until library administrators are able to secure separate and permanent funding for online searching. ${ }^{1}$

Sheila Dowd, John Whaley Jr., and Marcia Pankake offer three opposing arguments. Dowd equates providing online search services with spending money on multiple reserve copies. Every dollar librarians divert from acquisitions to online searches is money that will not be available to build a broad and balanced array of titles. ${ }^{2}$ Whaley argues that the practice of funding online searches from materials budgets has little to do with philosophy in most libraries. When funding is tight, he points out, librarians can more easily tap materials budgets funds than heavily encumbered operating budgets, thus making this a pragmatic process. ${ }^{3}$ Pankake agrees with Whaley and adds that materials budgets are vulnerable to "raids." She asserts that librarians are confusing the provision of access with the provision of information. Both activities are proper missions of the library, but each should have separate funding sources. ${ }^{4}$ In a 1987 follow-up to the 1986 CERL articles, Ann Bristow Beltran suggests that the underlying remote database from which an online search is extracted is itself a reusable resource. By charging remote database costs to the materials bud- get, librarians are helping to fund this resource and continue its availability. ${ }^{5}$

In 1990, Peggy Johnson surveyed members of the ARL on issues related to trends in materials budgets and published her findings in Materials Budgets in ARL Libraries, SPEC Kit \#166. ${ }^{6}$ She reports that libraries are using materials budgets in the following ways: computer files such as diskettes, mainframe tapes, and CD-ROM (87\% of respondents); remote database searching costs (32.9\%); and computer hardware $(15.2 \%)$. The study also surveyed librarians on the funding sources for materials budgets in their libraries and on which persons in the organization make allocation decisions.

In a 1993 article, Ross Atkinson asserts that the acquisitions budget should be integrated into the broader library and institutional budgetary process. ${ }^{7} \mathrm{He}$ suggests that the success librarians have enjoyed in protecting the purchasing power of materials budgets may be draining potential resources away from other library operating needs. He points out that libraries cannot thrive and prosper by increasing materials budgets alone, as if to say that information can be made accessible by merely purchasing it. Ironically, he argues, this channeling of resources exclusively into acquisitions budgets may now be working to the detriment of information services as a whole.

Nancy Eaton discusses financial issues related to collection development in an address at the 1993 Advanced Collection Management and Development Institute. ${ }^{8}$ She argues that the key to providing additional library funding is in developing greater cooperation among university libraries, media centers, computing centers, and telecommunications centers. This will in turn create economies of scale, less redundancy, and opportunities for departmental specialization. Eaton suggests that librarians need to harness automation synergies on campuses. Campus partners are not necessarily operating in a zero-sum environment in which 
one unit's gain automatically creates another unit's loss.

In a 1994 article, Jerry Campbell argues that the advent of technology applications in libraries necessitates the need for an entirely new budget model. ${ }^{9}$ In the early days, libraries successfully funded incremental advances in automation. However, the scope of funding needs for technology is now too great to absorb without a fundamental change in how librarians allocate resources. Given what he characterizes as the aversion most librarians have to drastic change, he proposes that they devise transitional budgets that reduce expenditures for personnel and print-on-paper, and correspondingly increase expenditures for technology and electronic distribution of information.

\section{Design and Response}

The literature survey produces a wealth of relevant position papers, but few reports of actual practice. This paper reports on the findings of a survey that measured how academic libraries currently allocate materials budgets and, specifically, to what extent libraries are using acquisition funds for what will be referred to as "materials support resources." Materials support resources are defined as those services and products that directly facilitate access to, and delivery of, information but do not represent analog or digital collection material. The survey also measured academic library heads' opinions on how libraries should be allocating scarce resources in an ideal scenario.

Asking librarians to reveal the extent to which they are spending "materials" budgets on items other than materials is somewhat forward and increases the possibility of a low-response rate. In an effort to ensure a meaningful response rate, the author utilized a formula-driven approach established by Don Dillman in his work Mail and Telephone Surveys: The Total Design Method. ${ }^{10}$

After extensive drafting, reviewing, and pretesting, the author sent the final survey to the heads of 230 academic libraries in the United States and Canada in September 1994. This target audience consisted of the 122 academic libraries surveyed biennially by the ACRL and the 108 academic members of the ARL. Respondents returned 177 surveys for a response rate of 76.9 percent. Survey results and a secondary analysis with separate responses for ARL and ACRL libraries are available from the author upon request.

\section{Findings \\ Background Characteristics}

Some background information on the demographic profile of the respondents helps to frame the survey data. Question one asked respondents to indicate the size of the library's materials budget. Approximately 55 percent of respondents reported a budget size of less than $\$ 3$ million. These libraries are referred to as "smaller libraries." The remaining 45 percent of the survey population reported a materials budget size of at least $\$ 3$ million. These are referred to as "larger libraries."

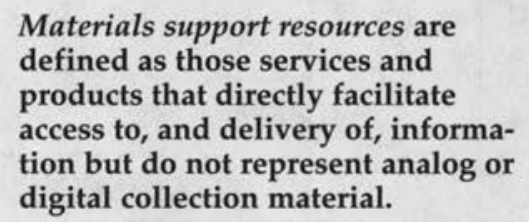

Materials support resources are defined as those services and products that directly facilitate access to, and delivery of, information but do not represent analog or digital collection material.

Knowing who responded to the survey may help the reader better appreciate the answers to opinion questions. Question eighteen asked respondents to identify their title within the library. Slightly more than 72 percent of respondents identified themselves as either deans, directors, university librarians, or campus heads of information technology. The remaining 18 percent identified themselves as either assistant/associate directors, heads of collection development, heads of administrative services, or heads of acquisitions, in that order of frequency. 


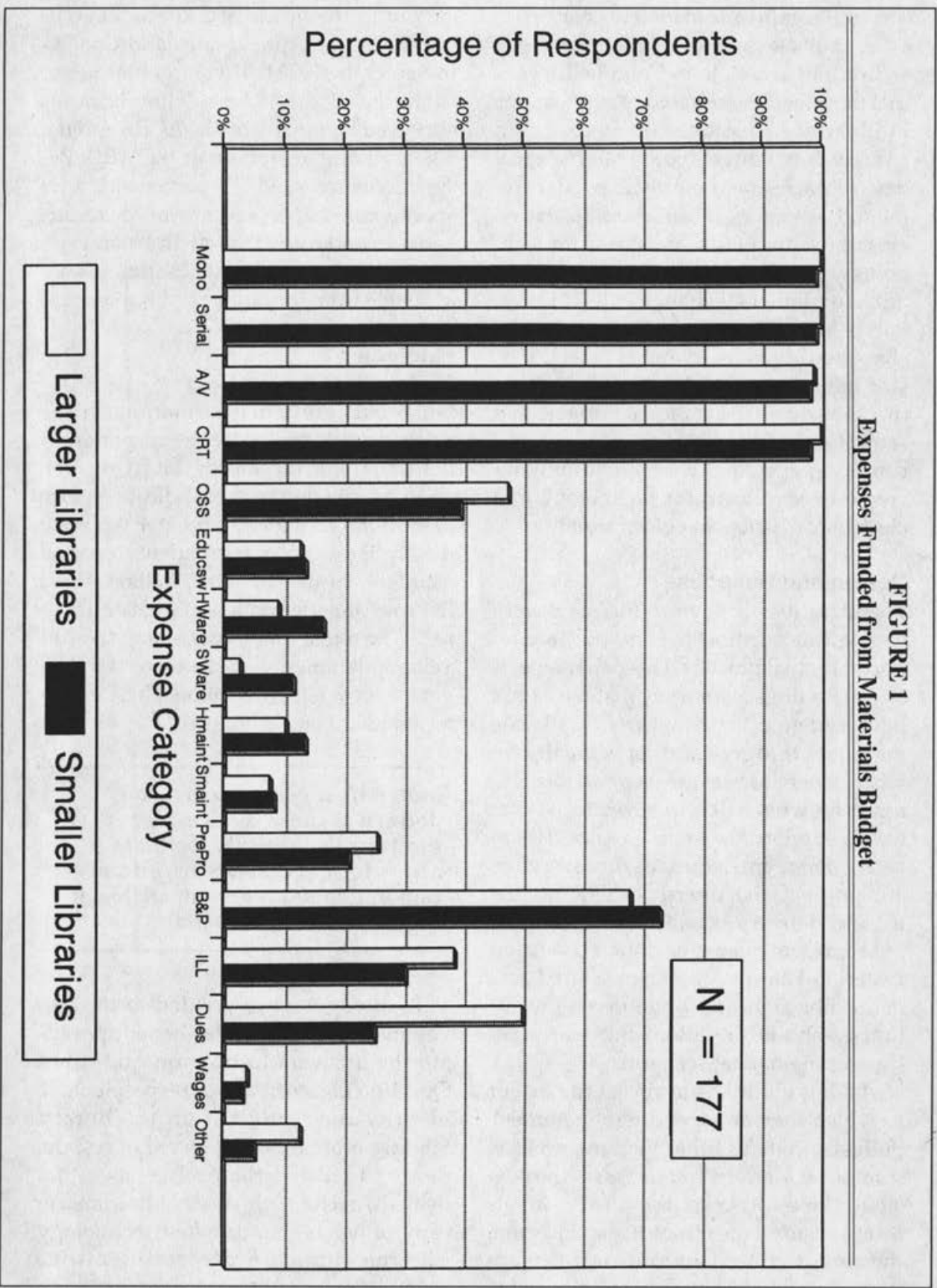

Question eight asked respondents to identify their parent institution affiliation. Roughly two-thirds, or 65.7 percent, of the survey population reported their institu- tion to be state supported, whereas 34.3 percent reported their institution to be privately supported. 


\section{Use of the Materials Budget}

The survey defined the term materials budget as that pool of funds used in the library to acquire and provide access to materials and sources of information. Question 2 asked what types of expenditures the library's materials budget funds. The question is restated here because of its importance to the study:

Q-2. For the most recent fiscal year, how many of the following types of expenditures were funded out of the materials budget? Circle as many as are applicable (circle number).

1) Monographs

2) Serials and Journals

3) Films, Videos, Sound Recordings, Microforms

4) Computer Readable Text, Indexes, Abstracts (CD-ROM, mainframe tapes, disks)

5) Remote Database Searching (online search costs)

6) Application Software for Patron Education

7) Computer Hardware (public access catalog terminals or PCs, CD ROM workstations, hardwiring costs, campus mainframe computers to support OPACs)

8) Computer Hardware Maintenance (vendor contracts or repair)

9) Computer Software to Facilitate Materials Access (loaders, drivers, etc.)

10) Computer Software Maintenance (vendor contracts)

11) Materials Preprocessing and Servicing (OCLC, SOLINET, etc.)

12) Binding and Preservation

13) Interlibrary Loan Expenses (copying charges, loan charges, other)

14) Membership Dues in National or Regional Library Networks

15) Wages (please specify which departments)

16) Other (please specify, if possible)

Virtually all respondents are purchasing monographs, serials, and audiovisual materials from the materials budget. Ap- proximately 99 percent of respondents are funding computer-readable text and indexes (CRT in figure 1) from the materials budget, whether it be CD-ROM, mainframe tape, or floppy disk media. Roughly forty-three percent of respondents are funding remote online search service (OSS) costs through the materials budget. Thirteen percent of respondents are charging the cost of application software (Educsw) to the materials budget.

Thirteen and 12.4 percent, respectively, of respondents fund hardware (HWare) and software (Sware) through the materials budget. Seven and nine percent, respectively, fund hardware (Hmaint) and software (Smaint) maintenance costs through the materials budget. Thirty-nine of the 177 survey respondents, or 22 percent, charge one or more of the aforementioned four automation-related expenditures to the materials budget. Only six respondents, or 3.4 percent, charge all four of these expenditures to the materials budget.

Roughly one-quarter $(23.2 \%)$ of libraries charge the costs of materials preprocessing (PrePro) to the materials budget. Seven out of ten $(70.6 \%)$ respondents charge binding and preservation (B\&P) costs to the materials budget, reflecting an established practice in academic libraries. One-third of libraries charge interlibrary loan expenses to the materials budget. Slightly more than one-third $(36.7 \%)$ charge membership dues to the materials budget. Only 3.4 percent pay wages from the materials budget. A handful of respondents wrote under "Other" that they charge document delivery costs to the materials budget.

Figure 1 shows the results in question two partitioned by library budget size. Larger libraries are slightly more likely than smaller libraries to charge remote OSS costs to the materials budget, by a margin of 47 to 40 percent. Larger libraries are twice as likely as smaller libraries to charge dues for consortial networks to materials budgets. Smaller libraries show 


\begin{tabular}{|c|c|c|c|c|c|}
\hline \multicolumn{6}{|c|}{$\begin{array}{l}\text { TABLE } 1 \\
\text { Percentage of Materials Budget Spent on Materials Support } \\
\end{array}$} \\
\hline & $\begin{array}{l}\text { Larger } \\
\text { Public }\end{array}$ & $\begin{array}{l}\text { Larger } \\
\text { Private }\end{array}$ & $\begin{array}{l}\text { Smaller } \\
\text { Public }\end{array}$ & $\begin{array}{l}\text { Smaller } \\
\text { Private }\end{array}$ & Overall \\
\hline None & $5.5 \%$ & $45.0 \%$ & $8.8 \%$ & $10.5 \%$ & $12.1 \%$ \\
\hline Less than $3 \%$ & 29.0 & 15.0 & 43.9 & 39.5 & 34.7 \\
\hline $3.0 \%$ to $5.9 \%$ & 30.9 & 20.0 & 17.5 & 26.3 & 24.8 \\
\hline $6.0 \%$ to $8.9 \%$ & 18.3 & 15.0 & 15.8 & 7.9 & 14.5 \\
\hline $9.0 \%$ to $11.9 \%$ & 14.5 & 0.0 & .7 .0 & 7.9 & 8.7 \\
\hline Over $12 \%$ & 1.8 & 5.0 & 7.0 & 7.9 & 5.2 \\
\hline Total & 100.0 & 100.0 & 100.0 & 100.0 & 100.0 \\
\hline Number in set $(\mathrm{N})$ & $\mathrm{N}=55$ & $\mathrm{~N}=20$ & $\mathrm{~N}=57$ & $\mathrm{~N}=38$ & $\mathrm{~N}=173^{\circ}$ \\
\hline
\end{tabular}

a higher tendency to charge hardwareand software-related costs to the materials budget.

In questions three and four, the author asked respondents to limit their answers to the subset of items numbered seven through sixteen in question two. These items constitute that set previously defined as the library's materials support resources. The results show that 12.1 percent of libraries charge none of these costs to the materials budget. Fifty-nine percent allocate trace to six percent of the materials budget to these costs. Twenty-eight percent of libraries spend at least six percent of the materials budget on materials support resources.

The data show that academic libraries overwhelmingly depend on university entitlements for funding of materials budgets and that, as a group, libraries generate very few independent funds.

Regression analysis reveals no statistical correlation between budget size and the degree to which the materials budget is spent on materials support resources. With budget size set as the independent variable $(X)$ and data from question three set as the dependent variable $(Y)$, the analysis produced an $\mathrm{r}$-squared value of less than .05. This suggests that less than five percent of the variation in the answers to question three is attributable to how the respondent answered question one. The analysis is limited in that it uses ranges of values rather than data points. The significance of this factor is unknown but would logically contribute to a lower r-squared value.

Table 1 segments the data from question three by institution size and type. Larger public institutions are slightly more likely than the group as a whole to fund materials support resources from the materials budget, whereas larger private libraries are the least likely. Fully 45 percent of larger private institutions spend none of their materials budgets on materials support resources. This does not suggest that size and affiliation are statistically predictive of spending behavior, but this may be a meaningful observation when viewed as part of an overall pattern.

In answering question four, survey respondents indicated to what extent they are dedicating a greater or lesser amount of their materials budget to materials support resources than they were three years ago. Slightly less than two-thirds $(62.9 \%)$ of the respondents responded that they spend about the same amount propor- 


\begin{tabular}{|c|c|c|c|c|c|}
\hline \multicolumn{6}{|c|}{$\begin{array}{c}\text { TABLE } 2 \\
\text { Percentage of Materials Budget Spent on Materials Support } \\
\text { Rate of Change Last Three (3) Years }\end{array}$} \\
\hline & $\begin{array}{l}\text { Larger } \\
\text { Public }\end{array}$ & $\begin{array}{l}\text { Larger } \\
\text { Private }\end{array}$ & $\begin{array}{l}\text { Smaller } \\
\text { Public }\end{array}$ & $\begin{array}{l}\text { Smaller } \\
\text { Private }\end{array}$ & Overall \\
\hline Stayed about same & $63.6 \%$ & $73.7 \%$ & $64.9 \%$ & $55.6 \%$ & $62.9 \%$ \\
\hline Increased & 25.5 & 15.8 & 19.3 & 27.7 & 23.6 \\
\hline Increased significantly & 5.4 & 10.5 & 7.0 & 13.9 & 8.2 \\
\hline Decreased & 5.5 & 0.0 & 8.8 & 2.8 & 5.3 \\
\hline Decreased significantly & 0.0 & 0.0 & 0.0 & 0.0 & 0.0 \\
\hline Total & 100.0 & 100.0 & 100.0 & 100.0 & 100.0 \\
\hline Number in set $(\mathrm{N})$ & $\mathrm{N}=55$ & $\mathrm{~N}=19$ & $\mathrm{~N}=57$ & $\mathrm{~N}=36$ & $\mathrm{~N}=170^{+}$ \\
\hline
\end{tabular}

tionately on materials support resources as compared to three years earlier. Roughly one-third ( $31.8 \%)$ spend a higher percentage on materials support resources, and approximately one in twenty (5.3\%) spend less proportionately.

Table 2 partitions the data from question four by institution size and affiliation. The differences are generally slight. Larger private libraries are the least likely to have increased or increased significantly the percentage of the materials budget spent on materials support resources in the past three years. This is logical given that 45 percent of larger pri- vate libraries are not utilizing any of the materials budget for materials support resources.

\section{External Factors}

Questions five, six, and seven examined some of the external factors that may be influencing how libraries allocate materials budgets. In question five, respondents identified the sources of funding for the materials budget in their library. The data show that academic libraries overwhelmingly depend on university entitlements for funding of materials budgets and that, as a group, libraries generate

\section{TABLE 3}

Sources of Materials Budget Funding

\begin{tabular}{lccccc}
\hline \hline & $\begin{array}{l}\text { Larger } \\
\text { Public }\end{array}$ & $\begin{array}{l}\text { Larger } \\
\text { Private }\end{array}$ & $\begin{array}{l}\text { Smaller } \\
\text { Public }\end{array}$ & $\begin{array}{l}\text { Smaller } \\
\text { Private }\end{array}$ & Overall \\
\hline $\begin{array}{l}\text { Educational } \\
\text { \& General (E\&G) }\end{array}$ & $88.1 \%$ & $81.4 \%$ & $90.2 \%$ & $85.0 \%$ & $87.7 \%$ \\
One-time funding & 2.8 & 3.8 & 4.7 & 0.3 & 2.8 \\
Overhead funds & 5.1 & 0.1 & 2.2 & 5.3 & 3.6 \\
Grants/endowments & 3.3 & 14.2 & 2.2 & 9.3 & 5.5 \\
Cost recoveries/other & 0.5 & 0.6 & 0.6 & 0.0 & 0.3 \\
Total* & $99.8 \%$ & $100.1 \%$ & $99.9 \%$ & $99.9 \%$ & $100.1 \%$ \\
Number in set (N) & $\mathrm{N}=57$ & $\mathrm{~N}=21$ & $\mathrm{~N}=56$ & $\mathrm{~N}=38$ & $\mathrm{~N}=174^{+}$ \\
\hline *Percentages do not always add to 100 due to rounding. \\
+Several institutions did not identify size and type. Figure in this column is total \\
number of institutions that answered the question. \\
\hline
\end{tabular}




\section{TABLE 4}

Sources of Funding for Materials Support Other Than Materials Budgets Percentage of Libraries Using Alternate Sources

\begin{tabular}{lccccc}
\hline \hline & $\begin{array}{c}\text { Larger } \\
\text { Public }\end{array}$ & $\begin{array}{l}\text { Larger } \\
\text { Private }\end{array}$ & $\begin{array}{l}\text { Smaller } \\
\text { Public }\end{array}$ & $\begin{array}{l}\text { Smaller } \\
\text { Private }\end{array}$ & Overall \\
\hline Library Operating & $98.2 \%$ & $90.0 \%$ & $94.6 \%$ & $100.0 \%$ & $95.8 \%$ \\
$\quad$ Funds & & & & & \\
$\begin{array}{l}\text { Library Capital Funds } \\
\text { Library Overhead }\end{array}$ & 76.8 & 75.0 & 67.9 & 78.8 & 73.8 \\
$\quad 19.6$ & 15.0 & 10.7 & 3.0 & 12.5 \\
$\quad \begin{array}{l}\text { Funds } \\
\text { Library Cost }\end{array}$ & 41.1 & 20.0 & 21.4 & 24.2 & 28.6 \\
$\quad \begin{array}{l}\text { Recoveries } \\
\text { Campus Computing }\end{array}$ & 17.9 & 35.0 & 17.9 & 21.2 & 20.8 \\
$\quad$ Centers & 16.1 & 15.0 & 5.4 & 18.2 & 13.1 \\
Gifts and Other & & & & & \\
\hline
\end{tabular}

very few independent funds. Recurring educational funds provide 87.7 percent of materials budget funds for the group as a whole. Grants and endowments provide the next largest source of funds at 5.5 percent, followed by overhead funds, one-time allocations, and cost recoveries, in that order.

Table 3 shows the data from question five broken down by institutional size and affiliation. Larger private libraries are the most successful in generating gift and endowment funds, deriving an average of 14.2 percent of materials budget funding from gifts and endowments. Smaller private institutions derive 9.3 percent of

\section{.... in the past three years, approxi- mately one-third of surveyed institutions increased that portion of the materials budget dedicated to materials support.}

materials funding from gifts and endowments. Comparable figures for larger public and smaller public libraries are 3.3 and 2.2 percent, respectively.

In question six, respondents indicated what sources, aside from the materials budget, customarily fund materials support resources. The data show that virtu- ally all libraries rely on operating funds to pay for materials support resources. Three-fourths of respondents $(73.8 \%$ ) use equipment or capital allocations. Onefifth $(20.8 \%)$ of the survey population cosponsors costs of materials support resources with campus computing centers. Sixteen respondents wrote that gifts and endowments support the cost of materials support resources.

Table 4 shows the same data broken down by size and affiliation. Larger publicly supported libraries are more likely than the population as a whole to use cost recoveries to fund materials support resources. This may partially be explained if the larger libraries are more likely to generate cost recoveries for any purpose. Over one-third of larger private libraries are cost-sharing materials support resources with campus computing centers, almost twice the rate of other institutions. This is noteworthy in light of the earlier finding that larger private libraries spend less of their materials budget on nondata and are the least likely of the four library types to change the percentage of the materials budget dedicated to nondata resources. Approximately one-fifth of larger public libraries use overhead funds to pay for materials support resources, versus only three percent of smaller private 
institutions. In summary, the larger libraries generally enjoy a wider variety of funding sources than the smaller libraries.

Question seven measured the amount of influence various external units exercise over how the materials budget is allocated. The data yielded no surprises, with library faculty ranked as the most influential group. Several respondents interpreted this question as asking how much influence external entities exert in establishing the monetary size of the materials budget. Variations in interpretation limit the usefulness of data from this question.

\section{Opinion Questions}

Questions nine through seventeen consisted of a series of statements of opinion. Respondents agreed or disagreed using a standard Likert scale. These questions gave respondents an opportunity to voice personal opinions on a wide variety of questions related to allocations of budgets in libraries. Answers provide an interesting contrast to practice.

Question nine generated strong agreement, with 83.4 percent of respondents agreeing or strongly agreeing that the practice of funding nonmaterials resources from the materials budget is a continuation of a long-standing trend. Question ten also registered strong agreement. When asked if it is natural that the materials budget absorb certain technology costs, seven out of ten respondents agreed or agreed strongly. Less than seventeen percent disagreed with question ten. Question eleven generated the greatest scattering of responses. Slightly less than 40 percent of respondents agreed or strongly agreed that their institution funds nonmaterials resources from the materials budget because they cannot find alternative funding sources. This is precisely the pragmatic rationale that Whaley suspected influenced many librarians in the late 1980 s to begin charging online search costs to the materials budget. ${ }^{11}$ However, this question regis- tered as much disagreement as agreement, with 41.3 percent disagreeing or strongly disagreeing. Interestingly, respondents from larger libraries were more likely to agree with this statement than those from smaller libraries. Forty-three percent of respondents from libraries with materials budgets exceeding $\$ 3$ million agreed or strongly agreed with question eleven, whereas 35.2 percent of respondents from smaller libraries agreed.

Questions twelve through fifteen measured views on broader budget issues. These questions measured the extent to which librarians are able or unable to distinguish between departmental units and the impact this may have on budgeting practices. The findings are mixed, with 77.9 percent of respondents agreeing that the separation between intralibrary departments is becoming less clear. However, only a slight majority (56.5\%) agree that departmental budgets are becoming less meaningful.

Questions sixteen and seventeen complement questions nine through eleven. In question sixteen, only 23.1 percent agree that academic library materials budgets should be limited to materials in a traditional sense, with 67 percent disagreeing. In question seventeen, 44.2 percent agree that using the materials budget for ever-increasing nonmaterials purchases will create a dependency that will undermine the materials budget and weaken the collection. Forty-five percent disagree with this statement.

\section{Observations and Comparisons with Earlier Studies}

The data reveal a mixed set of observations. As a whole, libraries are dedicating relatively small amounts of materials budgets to "materials support." Conversely, in the past three years, approximately one-third of surveyed institutions increased that portion of the materials budget dedicated to materials support. Comparisons between large and small institutions also are mixed. Of the four li- 
brary types identified in the study, smaller private institutions are the most likely to be changing the mix of the materials budget. However, regression analysis reveals no statistical correlation between library size and the degree to which libraries fund materials support from the materials budget.

In their responses to opinion questions, librarians show similarly ambivalent attitudes to those held by earlier authors in the 1980 s when asked about funding online search costs. In question ten, 70.3 percent of respondents agree that as the "container type" evolves, it is natural for certain technology costs to be absorbed by the materials budget. In question eleven, just under 40 percent of respondents state they fund nonmaterials resources through the materials budget because they are having difficulties finding the funding elsewhere. The difference between today's discussions and those of the 1980 s is largely one of scale. A decade ago, librarians spoke out on how to most appropriately fund online search costs totaling several or tens of thousands of dollars annually. In today's environment, librarians are struggling to fund support costs in the hundreds of thousands of annual dollars for medium-size libraries, and millions of annual dollars for research institutions. Libraries have reached a point where the issue of which internal source to use to fund materials support is becoming moot. They will be unable to pay for these spiraling costs from any internal source without a major infusion of funding or major budget reengineering. As Campbell points out, libraries have reached the point where they can no longer afford the full cost of automation and still maintain the status quo environment. ${ }^{12}$

Interestingly, librarians have contributed to this dilemma. As Atkinson (among numerous others) points out, some of the very successes libraries have had in the past twenty years in preserving the purchasing power of acquisitions budgets have quite possibly reduced funding for other, equally important areas of the library. ${ }^{13}$ If this is true, it is no wonder that some libraries are using materials budgets to fund purchases that are, in the opinion of some observers, more appropriately funded from other budgets. Furthermore, campus administrators may have developed the mistaken notion that the institution is adequately meeting the library's needs simply by maintaining acquisitions budgets.

\section{Scenarios for the Future}

Libraries, which face serious funding dilemmas and which do not have external funding available, may want to consider alternate scenarios. In the first scenario, the library radically reallocates internal resources, as advocated by Campbell. ${ }^{14}$ This is painful and may best be accomplished over time. In the second scenario, the library works collaboratively with campus computing units to cosponsor the costs of materials support. Both these scenarios implicitly recognize that distinctions between traditional library units are getting fuzzier. This is borne out in the answers to question fourteen, in which 77.9 percent of respondents agree that the separation between library departments is becoming more unclear. Other scenarios include enhanced fundraising and development efforts, and partnering with outside private interests.

Librarians need to recognize that they are no longer the exclusive gatekeepers of information access, storage, collection, and dissemination. At the same time, they need to promote, defend, and champion their mission on campus. By opening the doors to jointly sponsored funding of materials support with other campus units, it is hoped that libraries will secure new sources of funding. Finally, by looking closely at internal processes and reengineering, where necessary, librarians may be able to help solve some of their own funding problems and better position themselves for the future. 


\section{Suggestions for Further Study and Conclusion}

The statistical studies, which are published annually and biannually by ARL and ACRL, may offer additional information to augment this study. For instance, those studies could be used to estimate the amount of library materials budgets being spent on binding and preservation. This figure then could be compared to data from this study to provide a truer gauge of the current impact of nondata resources on materials budgets, exclusive of binding and preservation.

Mail surveys are difficult to design and evaluate, and this survey proved no exception. The primary difficulty stems from a lack of opportunity for surveyor and respondent to interact. An additional challenge arose from trying to gather both statistical data and opinion in one study, while also maintaining a reasonable length.

The survey response of 177 institutions presents a sufficient set of data from which to make some observations. However, as with any survey data, findings are qualified at best. Several respondents complained about a lack of definitions and imprecise language in the survey returns. Selected questions in some responses were unanswered. Fortunately, the number of unanswered questions did not exceed five percent of responses for any one question.

Some of the data subsets were small. Only twenty-one respondents fell into the classification of "larger private institution." Had one or two of these respondents answered questions differently, it would have affected the percentages in this subgroup significantly.

The findings of this study are based on survey data gathered in the fall of 1994 . Operating results are based on library financial data from fiscal years 1993-94. Events are happening quickly. Undoubtedly, the fiscal, technological, and political environment in our academic libraries will have changed by the time this study is published. The author hopes that this study will have retained some of its usefulness to the academic community, while also recognizing that the data may have historical value.

\section{Notes}

1. Jay Martin Poole and Gloriana St. Clair, "Funding Online Services from the Materials Budget and Reactions," College \& Research Libraries 47 (May 1986): 225-37.

2. Sheila Dowd, John H. Whaley Jr., and Marcia Jean Pankake,"Reactions to Funding Online Services from the Materials Budget,'" College \& Research Libraries 47 (May 1986): 230-32; reaction by Sheila Dowd.

3. Ibid., 232-34; reaction by John $\mathrm{H}$. Whaley Jr..

4. Ibid., 234-37; reaction by Marcia Jean Pankake.

5. Ann Bristow Beltran, "Funding Computer-Assisted Reference in Academic Research Libraries," Journal of Academic Librarianship 13 (Mar. 1987): 4-7.

6. Peggy Johnson, Materials Budgets in ARL Libraries, SPEC Kit \#166 (Washington, D.C.: ARL, 1990),

7. Ross Atkinson, "Crisis and Opportunity: Reevaluating Acquisitions Budgeting in an Age of Transition," Journal of Library Administration 19 (1993): 33-55.

8. Nancy L. Eaton, "Computing Resources: Opportunities and Challenges in Institutional Cooperation," in Collection Management and Development: Issues in an Electronic Era (Chicago: ALA, 1994): 80-91.

9. Jerry D. Campbell, "Getting Comfortable with Change: A New Budget Model for Libraries in Transition," Library Trends 42 (winter 1994): 448-59. 1978).

10. Don A. Dillman, Mail and Telephone Surveys: The Total Design Method (New York: Wiley,

11. Whaley, "Reactions to 'Funding,'" 234.

12. Campbell, "Getting Comfortable with Change," 450.

13. Atkinson, "Crisis and Opportunity," 36.

14. Campbell, "Getting Comfortable with Change," 449-50. 